\title{
The Effects of Higher Education in Economics, Law and Political Science on Perceptions of Responsibility and Sustainability
}

\author{
Niklas Harring, Cecilia Lundholm and Tomas Torbjörnsson
}

\begin{abstract}
Problems of environmental degradation are often conceptualized in terms of collective action dilemmas, and imply an increased demand for coordination and steering by public authorities. Social science is struggling with understanding how attitudes to collective action dilemmas and state intervention actually are formed. In the literature on environmental attitude formation, education is often claimed to be an important factor. It is argued for example that people with university degrees develop certain values essential for beliefs about personal responsibility and concern for the environment. Still there are a number of questions unanswered. For example, we know little about the effects of different educational programs. In this study we test the hypotheses by using a unique longitudinal data set based on surveys distributed to students in economics, law, and political science at seven universities in Sweden. Our results show a slight decrease in ascribed personal responsibility for environmental protection among the students after one semester. Instead, students ascribe an increased responsibility to various institutions and actors.
\end{abstract}

\footnotetext{
N. Harring $(\bowtie)$

Department of Political Science, University of Gothenburg,

Box 711, 40530 Gothenburg, Sweden

e-mail: niklas.harring@pol.gu.se

C. Lundholm · T. Torbjörnsson

Department of Humanities and Social Science Education, Stockholm University, 10691 Stockholm, Sweden

e-mail: cecilia.lundholm@hsd.su.se

T. Torbjörnsson

e-mail: tomas.torbjornsson@hsd.su.se
} 


\section{Keywords}

Higher education - Sustainability $\cdot$ Longitudinal data $\cdot$ Environmental support • Economics $\cdot$ Law $\cdot$ Political science

\section{Introduction}

Several of the most pressing environmental problems (e.g. climate-change, ocean acidification, and chemical pollution) are argued to be based on individual consumption choices and hence could be described in terms of large-scale collective action dilemmas, where individual rationality is at odds with collective rationality. As individual consumers we receive the benefits of our consumption while the costs are shared by the collective, in terms of environmental degradation (Dawes 1980; Dietz et al. 2002; Hardin 1968; Olson 1965). If people do not make sacrifices voluntarily, the intervention of a third actor, which in most cases would be the government, is necessary in order to achieve large-scale collective action (Mansbridge 2014). But such intervention is unlikely to be successful if people do not accept it. Hence for a sustainable trajectory, individuals need to be both prepared to make individual sacrifices for the environment, and/or be willing to accept and comply with governmental policy. How such sustainability norms can be created and shaped is therefore one of the most important questions that we face today.

Education is often put forth as a possible solution and a route to a more sustainable trajectory (United Nations 2005). Within the educational system this is a concern for everyone, from pre-school to higher education institutions. How education for sustainable development or education in general has an effect on environmental support is however disputed. In this report we focus on higher education where research show mixed results. Many studies claim that people with higher education (or more years of schooling) are more likely to show environmental support by choosing more environmentally sound consumer products, express environmental concern, and support environmentalism in general (Dietz et al. 1998; Franzen and Vogl 2013; Jones and Dunlap 1992; Klineberg et al. 1998; Koos 2011; Marquart-Pyatt 2012; Van Liere and Dunlap 1980). The suggested explanation is that higher education provides tools to understand the complexity of multifaceted problems of environmental degradation, such as climate change. Furthermore education is argued to generate new values and new priorities, and one such new priority is the importance of a healthy environment.

However, some studies conclude that there are no significant effects of education on pro-environmental policy support (e.g. Carman 1998) and there are also studies showing that people with more years of schooling are more likely to show environmental support on some measures but not on others (Newman and Fernandes 2015). In addition, recent studies have found that college students after one semester of studies in economics, law or political science do not feel more personal 
responsibility for protecting the environment, rather, if anything, the results indicate a slight decrease in ascribed personal responsibility for environmental protection (Harring and Jagers 2015. Davies et al., in preparation).

Here, we use the same empirical material as Harring and Jagers (2015) and Davies et al. (in preparation) — a two-wave longitudinal study of Swedish college students - to further investigate what happens to students' perception of sustainability after one semester of college studies. Given that most of previous studies have focused on the effects of education on environmental support in general, we aim to provide a more sophisticated analysis of education on environmental support and sustainability beliefs. What kind of perceptions about causes of environmental degradation do students develop after one semester, and which actors do they see as responsible for causing environmental problems and protecting the environment?

It is important for scholars trying to understand how to shape sustainability education, and sustainable higher education institutions, to understand what kinds of underlying perspectives that university programs provide. Higher education might have strong effects on students' perceptions and beliefs which are more complex than just whether they show more environmental support or not. The students in our study (economists, law and political science students), and their conceptualization of sustainability, are of particular interest since many of them will hold positions in society where important decisions about sustainability issues will be made.

\section{Higher Education and Environmental Support}

As discussed in the introduction, education has been argued to foster norms of sustainability and many countries and higher education institutions have adopted United Nations (2005) call for sustainable education. A central aspect of whether higher education institutions are in accordance with a sustainable trajectory is of course whether core education provided by higher education institutions actually promotes sustainability.

In this text we focus on Sweden, and in the Swedish Higher Education Act (SFS 1992) it is clearly stated that higher education institutions in Sweden shall promote sustainability. To what extent higher education actually breeds sustainability norms among the students is however unclear. Even though many studies show that years of schooling is an important determinant of environmental support (e.g. Van Liere and Dunlap 1980), there are other studies arguing that certain university programs generate more cynicism and egoistic values. For example, several studies show that students in economics are more egoistic than other student groups and other people in general. It is argued that students in economics are taught models based on rational choice theory, where actors are described as self-interested rational profit-maximizing actors, which in turn affect their view about themselves and others. The major dispute in this discussion is whether students in economics become more egoistic during their studies (treatment effect) or whether students 
with more egoistic values choose to study economics (selection effect) (Carter and Irons 1991; Frank et al. 1993; Frank and Schulze 2000; Frey and Meier 2003, 2005; Marwell and Ames 1981; Wang et al. 2011).

However, the potential negative effect of teaching rational choice theory is not limited to economics. Presenting a rather cynical view of political realities has also been argued to shape the views of political science students (Crawford 2007; Ostrom 1998; Steiner 1990), while students in law, being part of a very competitive and hierarchy-enhancing environment, are argued to develop egoistic and less egalitarian norms (Coulter et al. 2007; Grouzet 2014; Guimond et al. 2003; Sidanius et al. 2006). Thus, we have reasons to believe that students actually get more cynical after one semester of education, in the sense that they do not think that anyone can solve problems of environmental degradation, and they feel less responsibility.

H1: After one semester students in economics, law and political science become more cynical in the case of environmental protection.

Another debate within research on the effects of higher education revolves whether university studies are hierarchy-enhancing or hierarchy-attenuating (Chatard and Selimbegovic 2007). The results show that some programs, typically business schools, with disciplines such as law and economics, are hierarchy-enhancing while others, typically social science institutions, are hierarchy-attenuating (Guimond et al. 2003; Sidanius et al. 2006). Based on this research we have reason to believe that students who study at hierarchy-enhancing institutions develop stronger hierarchy norms and hence put larger confidence in elite actors, such as business actors and/or the government. If their studies also generate a belief that people in general are short-sighted this might generate an attitude that it is instead elite actors that have competence and power to actually achieve good outcomes. A closely related explanation would be that students perceive that a third party (or elite) intervention is necessary. If students recognize the collective action dilemma of environmental degradation this could trigger a demand for elite action in terms of government intervention (Harring 2016; Harring and Jagers 2013). We have reasons to believe that we will find stronger effects among economics and law students (hierarchy-enhancing) while less strong among social science students (hierarchy-attenuating, in our case political science students).

$\mathrm{H} 2:$ After one semester students in economics and law are more likely to think that elite actors have the competence and responsibility to protect the environment.

Another potential development among Swedish college students is that education provides them with more structural perspectives on societal problems. With a structural perspective they do not point at certain actors (not themselves, nor the government or anyone else), but rather claim that it is the system within which these 
actors act, that is the problem. Research has shown that different types of education influence where people place the responsibility for societal problems. For example, Guimond, Begin and Palmer (1989), Guimond and Palmer (1990) have shown that social science students are more likely to give structural explanations to problems of unemployment and poverty, while business school students are more likely to attribute this to individual factors. In one of their studies they found that social science students are even more likely than poor/unemployed to give attributions to structural factors. The authors believe that this can be explained by socialization. Social science students are taught that there are structural origins of these problems and are therefore more likely to provide structural explanations to the problem (Guimond et al. 1989; Guimond and Palmer 1990). Hence, a structural perspective is not about feeling personal responsibility or pointing at specific actors, but rather a view of an overarching perspective - the "system"- causing the problems.

H3: After one semester social science students are more likely to give a structural perspective on sustainability issues.

\section{Methods and Material}

We make use of unique two-wave longitudinal data from Swedish college students from seven different universities. The data were collected during their initial semester at the university. The first data collection was performed in the beginning of the semester, August/September 2014, and the second wave of data collection was performed in December/January 2014/2015, end of semester. The students were asked to complete the questionnaires in connection with their lectures. Participation was completely voluntary and students who participated received a cinema ticket.

As mentioned above we focus on three different types of higher education disciplines; economics (47\% of the sample); law (30\% of the sample) and political science ( $22 \%$ of the sample). In the group that we were able to match between the first and second survey $(\mathrm{N}=882)$, the majority were women $(63 \%)$. On a question about ideological position, $45 \%$ considered themselves as being on the right, $37 \%$ as being left, while $18 \%$ considered themselves as neither left nor right. A selection of the questions was also answered by a control group provided by the Citizens Panel at the LORE institute at the University of Gothenburg. ${ }^{1}$

In order to measure cynicism, attitudes to elite actors, and structural explanations we make use of a number of statements from the same question battery where the students can rate to what degree they agree with the statements. The responses are reported on a five-point scale from "strongly disagree" to "strongly agree".

\footnotetext{
${ }^{1}$ For a more elaborated discussion about the data see www.lore.gu.se.
} 


\subsection{Cynicism}

We measure and define cynicism in terms of students' perceptions of not having responsibility for protecting the environment - ascription of personal responsibility - and, secondly if they think that other actors have a responsibility (and/or can solve the problem of environmental degradation). We measure ascription of responsibility based on three questions; "My own lifestyle has contributed to the current environmental problems"; "I am co-responsible for protecting the world's environment"; and "I have no personal responsibility to protect the environment". The Cronbach's alpha value for these questions is quite low (0.53), we therefore chose to present the results statement by statement.

We also have a question that captures whether others are responsible, and the relationship between authorities and ordinary citizens: "Ordinary citizens and not just authorities and decision makers carry a great deal of responsibility for the environment".

\subsection{Views on Elite Actors}

In order to capture the respondents' view on elite actors we first have a question regarding responsibility of authorities: "Authorities and decision makers, not ordinary people, have the primary responsibility of preventing environmental destruction". We then have two questions about the role of business actors in the case of sustainability: "It is only the most environmentally friendly companies that survive on the market"; and "It is business actors that lead the development for a better environment". A first analysis of the questions shows that it does not make sense to build an index of attitudes of elites out of these questions as the Cronbach's alpha is very low (0.25). Hence, we review the results statement by statement (more on this in the results section).

\subsection{Structural Explanations}

Our last hypothesis concerns whether social science students are more likely to suggest structural explanations. We measure these structural explanations by two questions: "The organization of the current economic system is the most crucial question for the future of our environment, as this is what primarily affects the environment"; and "Reformation of economic structures is the key to managing our environmental problems", the Cronbach's alpha is good (0.75). However, we review these results also statement by statement.

In order to analyse the data and test the hypotheses we have performed a number of mean values comparisons for all students and also compared the means by discipline (economics, law and political science). Some of the questions are compared with results from the control group. 


\section{Results}

We find that even though all students, after one semester, are more likely to think that their"own lifestyle has contributed to current environmental problems" (mean value difference $\left.(\mathrm{mvd})=0.063^{*}\right)$ they are less likely to agree with the statement "I am co-responsible for protecting the world's environment" ( $\left.\mathrm{mvd}=-0.074^{*}\right)$ and more likely to agree with the statement "I have no personal responsibility to protect the environment" $\left(\mathrm{mvd}=0.077^{* *}\right)$. These results (presented in Table 1 ) to some extent indicate an increase of cynicism. Students are more likely to think that they contribute to the problem but do not feel responsible, although it is important to stress that the size of the effects can be interpreted as pretty small.

Furthermore, we note that results on the question "Ordinary citizens and not just authorities and decision makers carry a great deal of responsibility for the environment" ( $\mathrm{mvd}=-0.139 * * *)$ show a decrease in all student groups, which suggests that students do become more cynical or at least they see a decrease in the responsibility that ordinary citizens have vis-à-vis authorities for protecting the environment. So, who is responsible?

One of our hypotheses proposes that students in economics and law put higher confidence in elite actors. First, results on their attitudes toward the government suggest that students in general are more likely to agree with the statement: "Authorities and decision makers, not ordinary people, have the primary responsibility of preventing environmental destruction" $\left(0.215^{* * *}\right)$. These results can be compared with the control group where there is actually an increase as well, but it is much smaller $(0.09 * *)$. Focusing on the next elite group; business actors, we find that the students after one semester agree with both statements "It is only the most environmentally friendly companies that survive on the market" $(0.111 * * *)$ and "It is business actors that lead the development for a better environment" $\left(0.121^{* *}\right)$.

However, when scrutinizing these results further and looking specifically at each student group, we find interesting differences, as there is no substantial change among the political scientists. Political science students are also least likely in the sample to agree with the statement "It is business actors that lead the development for a better environment" (mean value $=2.75$ ). Yet, both law students (mean value $=3.115$ ) and economists (mean value $=3.146$ ) put more faith in business actors, and their faith in business actors increases after one semester of college studies. Hence we can see that different types of elite group matters and that political scientists have more faith in the government, while not in business actors.

The next hypothesis concerns whether political science students are more likely to suggest structural explanations after one semester. When studying the different student groups we actually see interesting differences again. Students in economics $(-0.094 *)$ are less likely to blame "the system" while political science students after one semester are more likely to think that reforming "the economic structures" is the key to managing environmental problems $\left(0.177^{\circ}\right)$ This is in line with results from previous research; social science students are more likely to suggest structural 
Table 1 Perceptions of responsibility in the case of sustainability among Swedish students during their first semester

\begin{tabular}{|l|l|l|l|l|} 
Wave 1 & Wave 2 & Difference & Significance & N \\
\hline
\end{tabular}

My own lifestyle has contributed to the current environmental problems

\begin{tabular}{l|l|l|l|l|l}
\hline Economists & 3.753 & 3.776 & 0.024 & ns & 380 \\
\hline Law students & 3.678 & 3.782 & 0.104 & $*$ & 289 \\
\hline Political scientists & 3.981 & 4.058 & 0.077 & ns & 207 \\
\hline Students total & 3.782 & 3.845 & 0.063 & $*$ & 876 \\
\hline Control group & 3.703 & 3.770 & 0.067 & $*$ & 887 \\
\hline
\end{tabular}

I am co-responsible for protecting the world's environment

\begin{tabular}{l|l|l|l|l|l}
\hline Economists & 4.447 & 4.371 & -0.076 & $*$ & 380 \\
\hline Law students & 4.413 & 4.358 & -0.056 & ns & 288 \\
\hline Political scientists & 4.604 & 4.507 & -0.097 & $*$ & 207 \\
\hline Students total & 4.473 & 4.398 & -0.074 & $* * *$ & 875 \\
\hline
\end{tabular}

I have no personal responsibility to protect the environment

\begin{tabular}{l|l|l|l|l|l}
\hline Economists & 1.707 & 1.742 & 0.034 & ns & 380 \\
\hline Law students & 1.696 & 1.806 & 0.111 & a & 289 \\
\hline Political scientists & 1.509 & 1.616 & 0.106 & $*$ & 206 \\
\hline Students total & 1.657 & 1.734 & 0.077 & $* *$ & 875 \\
\hline Ordinary
\end{tabular}

Ordinary citizens and not just authorities and decision makers carry a great deal of responsibility for the environment

\begin{tabular}{l|l|l|l|l|l}
\hline Economists & 4.318 & 4.186 & -0.131 & $* * *$ & 380 \\
\hline Law students & 4.298 & 4.130 & -0.170 & $* * *$ & 288 \\
\hline Political scientists & 4.332 & 4.221 & -0.111 & $* *$ & 208 \\
\hline Students-total & 4.314 & 4.175 & -0.139 & $* * *$ & 878
\end{tabular}

Authorities and decision makers, not ordinary people, have the primary responsibility of preventing environmental destruction

\begin{tabular}{l|l|l|l|l|l}
\hline Economists & 2.458 & 2.674 & 0.216 & $* * *$ & 380 \\
\hline Law students & 2.578 & 2.789 & 0.211 & $* *$ & 289 \\
\hline Political scientists & 2.512 & 2.729 & 0.217 & $* *$ & 206 \\
\hline Students-total & 2.510 & 2.725 & 0.215 & $* * *$ & 875 \\
\hline Control & 2.773 & 2.864 & 0.090 & $* *$ & 868
\end{tabular}

It is only the most environmentally friendly companies that survive on the market

\begin{tabular}{l|l|l|r|l|l}
\hline Economists & 2.018 & 2.103 & 0.084 & $*$ & 379 \\
\hline Law students & 1.886 & 2.121 & 0.235 & $* * *$ & 289 \\
\hline Political scientists & 1.887 & 1.872 & -0.015 & ns & 204 \\
\hline Students-total & 1.944 & 2.055 & 0.111 & $* * *$ & 872 \\
\hline
\end{tabular}

It is business actors that lead the development for a better environment

\begin{tabular}{l|l|l|r|l|l}
\hline Economists & 3.010 & 3.146 & 0.135 & $* *$ & 377 \\
\hline Law students & 2.923 & 3.115 & 0.192 & $* *$ & 287 \\
\hline Political scientists & 2.756 & 2.751 & -0.005 & ns & 205 \\
\hline Students-total & 2.921 & 3.043 & 0.121 & $* * *$ & 869 \\
\hline
\end{tabular}


Table 1 (continued)

\begin{tabular}{l|l|l|l|l|} 
Wave 1 & Wave 2 & Difference & Significance & N
\end{tabular}

The organization of the current economic system is the most crucial question for the future of our environment, as this is what primarily affects the environment

\begin{tabular}{l|l|l|r|l|l}
\hline Economists & 3.437 & 3.343 & -0.094 & $*$ & 382 \\
\hline Law students & 3.307 & 3.404 & 0.098 & a & 287 \\
\hline Political scientists & 3.667 & 3.706 & 0.039 & ns & 204 \\
\hline Students-total & 3.448 & 3.448 & 0.000 & ns & 873 \\
\hline Control & 3.704 & 3.709 & 0.005 & ns & 862 \\
\hline
\end{tabular}

To reform the economic structures are the key to managing our environmental problems

\begin{tabular}{l|l|l|r|l|l}
\hline Economists & 3.358 & 3.305 & -0.053 & ns & 380 \\
\hline Law students & 3.203 & 3.231 & 0.028 & ns & 286 \\
\hline Political scientists & 3.568 & 3.684 & 0.117 & a & 206 \\
\hline Students-total & 3.357 & 3.370 & 0.014 & ns & 872 \\
\hline Control & 3.681 & 3.696 & 0.015 & ns & 864
\end{tabular}

Comment Paired sample t-tests. For some of the statements non-parametric tests (Wilcoxon signed rank tests) have been performed. Ns not statistically significant, $p<0.10,{ }^{*} p<0.05, * * p<0.01$, $* * * p<0.001$. All estimates are based on five-point scales. For the exact wordings of the questions, see the methods section

explanations while business/economics students are less likely to do so (Guimond et al. 1989; Guimond and Palmer 1990).

\section{Concluding Remarks}

In summary, the results show that students change their positions on several of the statements. We find a weak decrease in their feeling of personal responsibility and that ordinary citizens in general are responsible. Instead, they are more willing to put confidence in other actors and institutions, and in change of structures.

Firstly, we find interesting differences between students in economics and law, and students in political science. Political science students put more confidence in the government while students in economics and law put more confidence in business actors. One potential explanation would be that political scientists to a large extent study government and policy, and therefore the acceptance of state intervention increases, while students in economics study markets and therefore gain more confidence in market actors.

Secondly, political science students are more likely to give structural perspectives on sustainability issues, while economists are less likely to do so. Whether or not this encourages the individual student to act for more sustainability would be an interesting area for future research. Agreeing with the statement "To reform the economic structures is the key to managing our environmental problems" and mistrusting business actors might be related to each other. It is maybe less likely to 
believe that business actors can lead change towards sustainability if you think that the economic structures need to be reformed. But that is to a large extent dependent on how students actually interpret the statement. Students within different disciplines can actually interpret the statement differently, as reforming economic structures could imply opposing positions such as both regulation of markets and privatization.

Finally, we believe that these results contribute to the debate on the effects of higher education on environmental support in two ways. First, our results show that higher education provides students with new views on sustainability, and that these are more nuanced than just reporting whether students show more or less environmental support. Second, we make use of a longitudinal dataset whereas much of the previous research on higher education and environmental support has used cross-sectional data. One limitation however with our study is of course that we only study the educational effects of one semester. On the other hand, our results show that education in economics, law and political science have various effects after only one semester, and if we think of these effects in terms of socialization, they would potentially increase over time (see discussion in Chatard and Selimbegovic 2007).

Environmental degradation is a societal problem. It is the organization of society and the actions of individuals living within these societies that generate environmental degradation; hence it is societies that can solve these problems. Students, both as citizens and professionals, will play an important role in how society tackles challenges of sustainability. Here, we have particularly reported educational effects of studies in economics, law and political science on students' views on responsibility and change towards sustainability. Our results are important when looking at how to improve sustainability education, and for bettering our understanding of its role in societal change. Improving our knowledge of the kinds of knowledge, perspectives, and tools, that major university programs provide are of importance for building environmentally sustainable societies.

\section{References}

Carman, C. J. (1998). Dimensions of environmental policy support in the United States. Social Science Quarterly (University of Texas Press), 79(4), 717-733.

Carter, J. R., \& Irons, M. D. (1991). Are economists different, and if so, why? The Journal of Economic Perspectives, 5(2), 171-177.

Chatard, A., \& Selimbegovic, L. (2007). The impact of higher education on egalitarian attitudes and values: Contextual and cultural determinants. Social and Personality Psychology Compass, 1(1), 541-556.

Coulter, I. D., Wilkes, M., \& Der-Martirosian, C. (2007). Altruism revisited: A comparison of medical, law and business students' altruistic attitudes. Medical Education, 41(4), 341-345.

Crawford, S. E. S. (2007). Will we ruin them for (civic) life? Analyzing the impact of teaching rational choice in introductory courses. PS: Political Science \& Politics, 40(02), 387-391.

Dawes, R. M. (1980). Social dilemmas. Annual Review of Psychology, 31, 169-193.

Davies, P., Harring, N., \& Lundholm, C. (in preparation). Does knowledge affect the choice of environmental policy instruments (EPI) among economics students? 
Dietz, T., Dolšak, N., Ostrom, E., \& Stern, P. C. (2002). The drama of the commons. In E. Ostrom, T. Dietz, \& N. Dolšak et al (Eds.), The drama of the commons. Washington DC: National Academy Press.

Dietz, T., Stern, P. C., \& Guagnano, G. A. (1998). Social structural and social psychological bases of environmental concern. Environment and Behavior, 30(4), 450-471.

Frank, B., \& Schulze, G. G. (2000). Does economics make citizens corrupt? Journal of Economic Behavior \& Organization, 43(1), 101-113.

Frank, R. H., Gilovich, T., \& Regan, D. T. (1993). Does studying economics inhibit cooperation? The Journal of Economic Perspectives, 7(2), 159-171.

Franzen, A., \& Vogl, D. (2013). Two decades of measuring environmental attitudes: A comparative analysis of 33 countries. Global Environmental Change, 23(5), 1001-1008.

Frey, B. S., \& Meier, S. (2003). Are political economists selfish and indoctrinated? Evidence from a natural experiment. Economic Inquiry, 41(3), 448-462.

Frey, B. S., \& Meier, S. (2005). Selfish and indoctrinated economists? European Journal of Law and Economics, 19(2), 165-171.

Grouzet, F. M. E. (2014). Development, changes and consolidation of values and goals in business and law schools the dual valuing process model. The Oxford Handbook of Work Engagement, Motivation, and Self-Determination Theory M. Gagné, Oxford University Press.

Guimond, S., Begin, G., \& Palmer, D. L. (1989). Education and causal attributions: The development of "person-blame" and "system-blame" ideology. Social Psychology Quarterly, 52(2), 126-140.

Guimond, S., Dambrun, M., Michinov, N., \& Duarte, S. (2003). Does social dominance generate prejudice? Integrating individual and contextual determinants of intergroup cognitions. Journal of Personality and Social Psychology, 84(4), 697-721.

Guimond, S., \& Palmer, D. L. (1990). Type of academic training and causal attributions for social problems. European Journal of Social Psychology, 20(1), 61-75.

Hardin, G. (1968). The tragedy of the commons. Science, 162, 1243-1248.

Harring, N., \& Jagers, S. C. (2013). Should we trust in values? Explaining public support for pro-environmental taxes. Sustainability, 5(1), 210-227.

Harring, N., \& Jagers, S. C. (2015). Why and how higher education affects attitudes to environmental state intervention. Conference paper. Midwest Political Science Association Annual Meeting, April 2015, Chicago.

Harring, N. (2016) Reward or punish? understanding preferences toward economic or regulatory instruments in a cross-national perspective. Political Studies, 64(3).

Jones, R. E., \& Dunlap, R. E. (1992). The social bases of environmental concern: Have they changed over time? Rural Sociology, 57(1), 28-47.

Klineberg, S. L., McKeever, M., \& Rothenbach, B. (1998). Demographic predictors of environmental concern: It does make a difference how it's measured. Social Science Quarterly (University of Texas Press), 79(4), 734-753.

Koos, S. (2011). Varieties of environmental labelling, market structures, and sustainable consumption across Europe: A comparative analysis of organizational and market supply determinants of environmental-labelled goods. Journal of Consumer Policy, 34(1), 127-151.

Mansbridge, J. (2014). The role of the state in governing the commons. Environmental Science \& Policy, 36, 8-10.

Marquart-Pyatt, S. T. (2012). Contextual influences on environmental concerns cross-nationally: A multilevel investigation. Social Science Research, 41(5), 1085-1099.

Marwell, G., \& Ames, R. E. (1981). Economists free ride, does anyone else? Experiments on the provision of public goods, IV. Journal of Public Economics, 15(3), 295-310.

Newman, T. P., \& Fernandes, R. (2015). A re-assessment of factors associated with environmental concern and behavior using the 2010 General Social Survey. Environmental Education Research, 1-23.

Olson, M. (1965). The logic of collective action: Public goods and the theory of groups. Cambridge: Harvard University Press. 
Ostrom, E. (1998). A behavioral approach to the rational choice theory of collective action. The American Political Science Review, 92(1), 1-22.

SFS. (1992). Högskolelag (the higher education act), SFS 1992:1434. Stockholm, Sweden: Department of Education.

Sidanius, J., Sinclair, S., \& Pratto, F. (2006). Social dominance orientation, gender, and increasing educational exposure1. Journal of Applied Social Psychology, 36(7), 1640-1653.

Steiner, J. (1990). Rational choice theories and politics: A research agenda and a moral question. PS: Political Science \& Politics, 23(01), 46-50.

United Nations. (2005). 59/237. United Nations decade of education for sustainable development. United Nations General Assembly, New York NY 24 February, 2005, United Nations.

Van Liere, K. D., \& Dunlap, R. E. (1980). The social bases of environmental concern: A review of hypotheses, explanations and empirical evidence. The Public Opinion Quarterly, 44(2), 181-197.

Wang, L., Malhotra, D., \& Murnighan, J. K. (2011). Economics education and greed. Academy of Management Learning \& Education, 10(4), 643-660.

\section{Author Biographies}

Niklas Harring is a researcher and lecturer at the Department of Political Science, University of Gothenburg. He is affiliated to the Department of Humanities and Social Science Education, Stockholm University, and The Centre for Collective Action Research, University of Gothenburg

Cecilia Lundholm is professor in educational science with a specialisation in teaching and learning in the social sciences at the Department of Humanities and Social Science Education, Stockholm University

Tomas Torbjörnsson is a PhD in educational science at the Department of Humanities and Social Science Education, Stockholm University 